
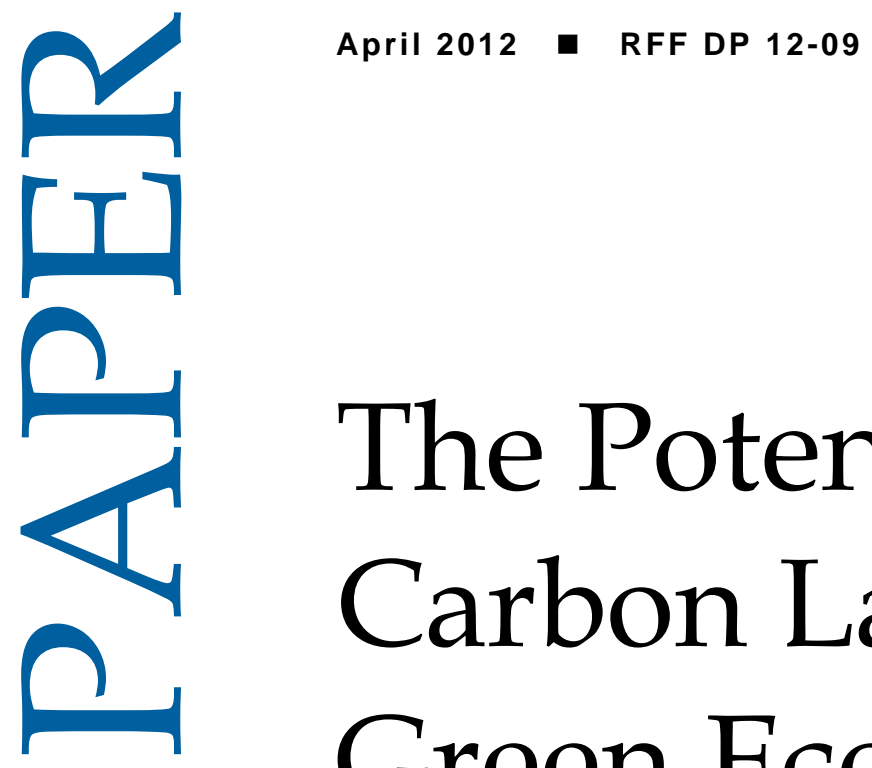

\title{
The Potential Role of Carbon Labeling in a Green Economy
}

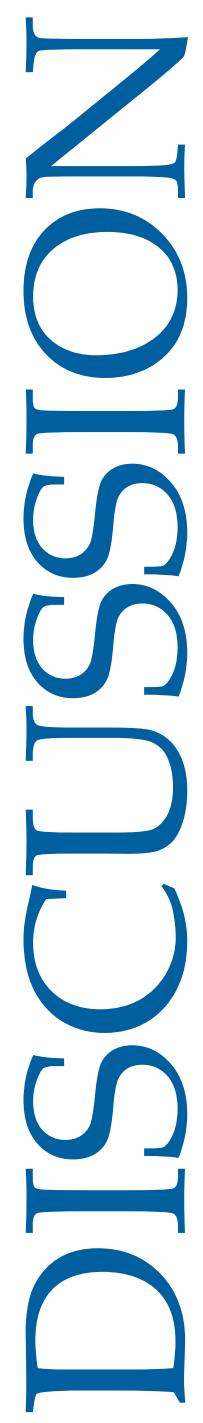

Mark A. Cohen and Michael P. Vandenbergh 


\title{
The Potential Role of Carbon Labeling in a Green Economy
}

\author{
Mark A. Cohen and Michael P. Vandenbergh
}

\begin{abstract}
Over the past several years, labeling schemes that focus on a wide range of environmental and social metrics have proliferated. Although little empirical evidence has been generated with respect to carbon footprint labels, much can be learned from our experience with similar product labels. We first review the theory and evidence on the influence of product labeling on consumer and firm behavior. Next, we consider the role of governments and nongovernmental organizations, concluding that global, multistakeholder organizations have a critical part to play in setting protocols and standards. We argue that it is important to consider the entire life cycle of a product being labeled and develop an international standard for measurement and reporting. Finally, we examine the potential impact of carbon product labeling, discussing methodological and trade challenges and proposing a framework for choosing products best suited for labeling.
\end{abstract}

Key Words: carbon labels, voluntary disclosure, consumer behavior, life-cycle analysis, rebound effect, leakage

JEL Classification Numbers: D82, F18, K32, L15, M31, Q54

(C) 2012 Resources for the Future. All rights reserved. No portion of this paper may be reproduced without permission of the authors.

Discussion papers are research materials circulated by their authors for purposes of information and discussion. They have not necessarily undergone formal peer review. 


\section{Contents}

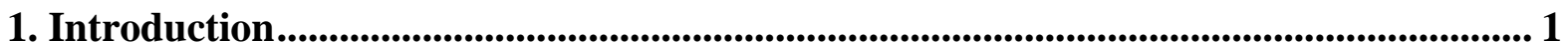

2. Economic Theory of Information and Product Labels ........................................................... 2

2.1 Products with Public and Private Attributes ………………………………………..... 4

2.2 Role of Third Parties ........................................................................................ 5

3. Evidence on Green Labels................................................................................................................. 6

3.1 Industry and Market Studies ............................................................................... 6

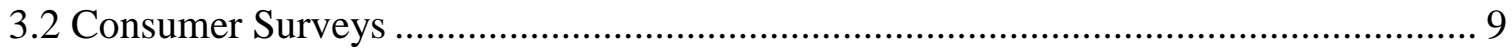

4. Potential Impact of Carbon Labels ................................................................................................... 10

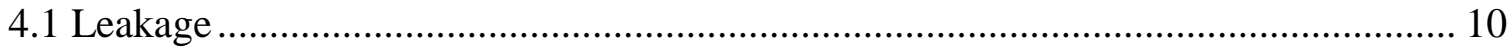

4.2 Rebound Effect versus Increasing Social Norm for Carbon Reductions.................... 12

4.3 Can Consumer Product Labeling Really Have an Impact? ....................................... 13

5. Practical Issues .................................................................................................................................... 14

5.1 Methodological Challenges ................................................................................... 14

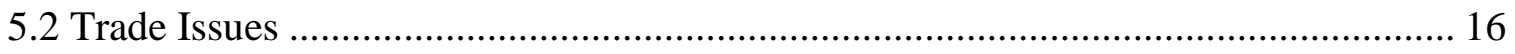

5.3 Product Label Design Issues ................................................................................ 20

5.4 Which Products Should Be Labeled? ................................................................. 22

6. Concluding Remarks ...................................................................................................................... 24

References......................................................................................................................................... 26 


\title{
The Potential Role of Carbon Labeling in a Green Economy
}

\author{
Mark A. Cohen and Michael P. Vandenbergh*
}

\section{Introduction}

Growing consumer interest in "green products" has led many companies to develop and market products with environmental attributes. In 2007, the U.S Patent and Trademark Office saw more than 300,000 applications for green-related brand names, logos, and taglines (Ottman 2011, 35). The number of new products labeled with the word(s) "sustainable," "sustainability," "environmentally friendly," or "eco-friendly" increased from 100 in 2004 to 526 in 2008, with an additional 450 product launches in the first four months of $2009 .{ }^{1}$ Representing a 39 percent increase from the previous year, 6,902 products on U.S. shelves in 2010 had some type of environmental claim, including 89 claiming to be carbon neutral (Mintel Group 2011, Figure 1).

Although the growth of niche brands such as Seventh Generation and Burt's Bees continues unabated, perhaps even more important is the movement by mainstream consumer product companies and retailers to promote green products. Recent examples include KimberlyClark's Scott Naturals (household paper products made from recycled material) ${ }^{2}$ and Proctor \& Gamble's goal of $\$ 50$ billion in cumulative sales of "sustainable innovation products" by $2012 .^{3}$

A significant and growing proportion of the sustainability-related product claims are now focusing on carbon emissions and climate change. Moreover, carbon labeling of products is

\footnotetext{
* Cohen, Professor of Management and Law, Vanderbilt University, and University Fellow, Resources for the Future. mark.cohen@owen.vanderbilt.edu. Vandenbergh, Professor of Law and Director, Climate Change Research Network, Vanderbilt Law School. michael.vandenbergh@ vanderbilt.edu.

We gratefully acknowledge the research assistance of Madeline Gottlieb and Marcy Nicks Moody. Helpful comments were received from Jeffrey Dunoff, Will Martin, and Sharon Shewmake. All remaining errors are those of the authors.

1 "Green Is the New Black," Adweek, June 24, 2009, http://www.adweek.com/news/advertising-branding/greennew-black-105996.

2 “Kimberly-Clark Announces Nationwide Launch of Scott Naturals," press release, April 8, 2009 , http://investor.kimberly-clark.com/releasedetail.cfm?ReleaseID=375980.

3 “Proctor \& Gamble Deepens Corporate Commitment to Sustainability," press release, March 26, 2009, http://www.pginvestor.com/phoenix.zhtml?c=104574\&p=irol-newsArticle\&ID=1270272. The company has since released an even more aggressive long-term vision that includes use of 100 percent renewable energy and 100 percent renewable or recycled materials for all products and packaging. See "Proctor \& Gamble Unveils New Sustainability Vision," press release, September 27, 2010, http://www.pginvestor.com/phoenix.zhtml?c=104574\&p=irol-newsArticle\&ID=1475092\&highlight=sustainability.
} 
gaining considerable interest. Pilot programs are being implemented in the United Kingdom, Switzerland, Japan, and other countries, and there are proposals to expand and standardize such programs globally (see Vandenbergh and Cohen 2010; Vandenbergh et al. 2011).

This paper examines the role of carbon product ("carbon footprint") labeling in promoting a green economy. While little empirical evidence has yet been generated with respect to carbon footprint labels, much can be learned from our experience with similar product labels. We first review the theory and evidence on the role of product labeling in affecting product design and consumer behavior. Next, we consider the role of governments, concluding that whether labeling is mandatory or voluntary, either governmental institutions or global, multistakeholder organizations have a critical part to play in setting protocols and carbonlabeling standards. We argue that it is important to consider the entire life cycle of a product being labeled and have one standard for measurement and reporting. Finally, we look at the potential impact of carbon product labeling, considering three important issues. First, we examine the methodological challenges associated with developing credible carbon footprint labels. Second, we consider the potential trade issues associated with carbon footprint labels. Finally, we sketch out an initial framework for determining which products might be most appropriate for carbon footprint labeling based on the potential aggregate reduction in carbon emissions.

\section{Economic Theory of Information and Product Labels}

The economic theory behind the demand for consumer product labels is well established. A traditional utility-maximizing model of consumer behavior assumes that the rational consumer will choose a combination of price and quality that is consistent with her utility function and constraints. An important assumption of utility maximization is that consumers have perfect information about the price and quality they face. But although consumers easily can determine quality attributes, or "search" goods, such as color or size, they do not necessarily observe "credence" goods - the ingredients of a product and their potential harm to the consumer's (or public's) health - either at the point of purchase or through casual experience (Nelson 1970; Darby and Karni 1973). The role of product labels is thus to turn a "credence" attribute into a "search" attribute so that consumers easily can compare and make more informed (utilitymaximizing) decisions.

For consumers, if the value of additional information exceeds the cost of search, they will demand this information and use it in their purchase decisions. Consumer demand for information on credence attributes also is predicated on the assumption that consumers know this 
attribute exists and might vary by product. In other words, in order to demand information, consumers need to know the value of it.

The supply side of the market is more complex. What are the incentives for firms to supply this information? Firms whose products possess a credence attribute with a positive benefit to consumers have an incentive to disclose and thus turn this latent value into a search attribute that presumably will increase sales. Profit-maximizing firms will thus weigh potential increased revenues against the cost of testing and providing information. In addition to directly increasing sales through higher consumer demand, however, firms also might benefit from improved relationships with regulators and other stakeholders that might positively impact profits in other ways.

If there is no cost to disclosure and consumers can verify or trust these disclosures, all sellers will disclose their quality for fear that consumers will otherwise infer that no disclosure means "lowest quality" (Grossman 1981). ${ }^{4}$ However, if it is costly to verify claims, every firm has an incentive to claim that their products are high quality. This might take the form of fraudulent claims or more subtle attempts at "greenwashing," whereby firms selectively disclose information that ultimately misleads consumers into thinking that the product is "greener," or higher quality, than it is. ${ }^{5}$ Darby and Karni (1973) recognized this problem and examined the potential role of third-party monitors to evaluate and report on credence qualities. They conclude that if the value of information is high enough to consumers, "high-quality" firms will find it in their interest to disclose this information, and a market will develop for third-party monitorswhether governmental, private, or nonprofit — to verify the truthfulness of this information. As Darby and Karni (1973) note, there is no inherent reason why this third-party monitor needs to be the government. In fact, they conclude that the private (or non-profit) sector could be as effective and potentially more effective than a government monitor.

A related literature examines firm incentives to voluntarily disclose credence product attributes in product-differentiated markets. As Ippolito and Mathios (1990) show, if one firm can credibly claim to have a better-quality product (e.g., one that is pesticide free), then the

\footnotetext{
${ }^{4}$ See Dranove and Jin (2010) for an extensive review of the literature on quality disclosure and certification.

${ }^{5}$ Lyon and Maxwell $(2011,9)$ define greenwashing as “...fundamentally about misleading consumers and investors by telling the truth, but not the whole truth. This suggests a model in which the firm discloses verifiable information, but may choose to withhold facts that do not reflect favorably on it, thereby persuading outsiders that the firm's performance is better than it is in reality."
} 
implication to consumers is that competing products without that claim do not have that positive attribute. Hence, there is an incentive for all firms to compete on that dimension. Ultimately, all firms but the lowest quality will thus have an incentive to disclose. As noted above, the credibility of firms' claims about credence attributes is a concern.

Baksi and Bose (2007) consider whether self-reporting of credence attributes (with governmental monitoring and punishment of cheaters) is preferable to third-party certification. Since both are costly, their results depend on these costs as well as the relative market share of "green" versus "brown" firms. They conclude that self-reporting is preferable when the market share of "green" firms is large enough that any loss from cheating by "brown" firms is outweighed by the cost of monitoring by third parties. A more realistic scenario, however, is that the potential cheating by "brown" firms will make mandatory third-party certification for all firms a more preferable outcome.

\subsection{Products with Public and Private Attributes}

While the early information disclosure literature envisioned attributes that directly benefit consumers, such as nutrition labeling or health risks, consumers also may demand credence goods that have a "public" good component, such as environmental protection. Consumer demand for such attributes may arise either from altruism or the "warm glow" associated with spending money on environmental protection (Andreoni 1990).

Firms also have an incentive to disclose these public attributes of their products in some cases. Following the earlier work on voluntary disclosure, Ibanez and Grolleau (2008) consider the case of eco-labels and show that as long as it is more costly for the "polluting" firm to obtain the label than the "clean" firm, the latter will obtain the label, and pollution will be reduced. However, as Ibanez and Grolleau caution, unless consumers are all altruists, eco-labels will be only a partial solution to environmental externalities.

Many environmental attributes will have private and public value. For example, products that use less toxic chemicals might have both direct health benefits as well as benefits to the environment. One important aspect of products that have both types of value is that the consumer oftentimes has a choice of purchasing this bundled product or purchasing the products separately. For example, instead of purchasing a "green" product, a consumer might purchase a less expensive product without an environmental benefit and instead donate to an environmental cause. Kotchen $(2005,2006)$ examines this case and provides some interesting insights into the way in which consumer product choice and environmental protection interact. It is possible, for 
example, that the availability of new "green" products will reduce donations (or other expenditures on environmental protection) as consumers shift their discretionary budget away from donations and into consumer products with environmental attributes that are more expensive. This has been termed the "rebound effect."

On the other hand, it is possible that the availability of new "green" products will provide information to consumers about the relative importance of certain environmentally friendly behaviors and thus increase the demand for environmental protection expenditures through either donations or political pressure (Kals et al. 1999; Maiteny 2002). In other words, it is important to know whether "green" products are substitutes for or complements to other environmental protection activities.

\subsection{Role of Third Parties}

As noted above, third-party monitors are critical in information markets because they allow firms to credibly disclose product information that consumers might not otherwise believe. However, third parties may serve other important purposes in information markets. Organizations such as Consumer Reports develop the expertise to analyze and report on product attributes using their own judgment and criteria. Retailers also may adopt a similar role in screening which products to carry or which to label the most environmentally friendly. Instead of doing considerable research to understand and compare product attributes, consumers may rely on these sources to rank products.

In the context of a public attribute or externality, third parties might play a different role of aggregating consumer interests. These third parties might reduce the transactions costs associated with collective action and help to overcome the free-rider problem inherent in individual purchase decisions involving a public good. For example, pressure by an environmental group and the threat of boycotts might induce firms to improve the environmental footprint of their products - or of products they put on their shelves - even in the absence of direct consumer demand signals (Baron and Diermeier 2007). Lenox and Eesley (2009) provide evidence on the role of nongovernmental organization boycotts and other forms of pressure on firm behavior.

Third-party eco-labeling and certification organizations — oftentimes with competing goals and conflicting interests - have proliferated in recent years. Ottman $(2011,165)$ reports there are currently more than 400 different eco-labels or certification schemes in 207 countries. Third-party verification is only as good as the third-party itself. Some of these groups are 
industry sponsored, while others are independent and subject to rigorous and transparent multistakeholder scrutiny. This proliferation easily can lead to consumer confusion and frustration because it requires expertise to know the difference between paper labeled with the "Forest Stewardship Council" versus the "Sustainable Forest Initiative," for example. The Natural Resources Defense Council has attempted to collect these various labels (and less rigorous marketing claims) and provides its own ranking of third-party labels. ${ }^{6}$ Organizations also have formed to set industry standards for voluntary product certification schemes. ${ }^{7}$

\section{Evidence on Green Labels}

Studies on the effectiveness of green labels generally do not satisfy the standards of rigorous empirical research because they lack random assignment or quasi-experimental designs. As a result, they fail to establish the causal relationship between green labels and environmental outcomes. Instead, the nature of the evidence falls into two categories: industry and market studies of product sales; and consumer surveys of label awareness, use, and stated preferences.

\subsection{Industry and Market Studies}

Perhaps one of the most studied programs is the U.S. Energy Star label, a public-private partnership in which the U.S. Department of Energy certifies consumer products that meet certain energy-efficiency criteria. ${ }^{8}$ According to the 2009 Residential Energy Use Survey conducted by the U.S. Energy Information Administration, market penetration of Energy Star appliances is about 40 percent for refrigerators, dishwashers, and clothes washers. ${ }^{9}$ The U.S. Environmental Protection Agency claims that in 2006 the Energy Star program helped to reduce 37.6 million metric tons of carbon emissions, although an Inspector General report has questioned the accounting methods used to generate the agency's estimates (U.S. EPA 2008). Brown et al. $(2002,515)$ estimates that the Energy Star label in the U.S. has reduced carbon

\footnotetext{
6 See http://www.nrdc.org/living/labels/.

7 One example is ISEAL; see www.isealalliance.org.

8 The Energy Star label generally applies to products with energy usage that is at least 25-30 percent below mandatory requirements.

${ }^{9}$ Data compiled from 2009 Residential Energy Consumption Survey, Table HC3.2, available at http://www.eia.gov/consumption/residential/data/2009/. Of those households who report that they have a refrigerator, 37.3 percent claim it is Energy Star. The corresponding figures are 40.3 percent for dishwashers and 44.0 percent for clothes washers.
} 
emissions by 150 million metric tons between 2001 and 2010, an amount that "represents about $4 \%$ of carbon emissions for the residential and commercial sectors over the same period."

All these estimated reductions are based on the market penetration of Energy Star labels and engineering-based estimates of product usage and emissions. Thus, while we know that Energy Star appliances have lower energy usage and lower carbon emissions than competing products, we do not know whether these products would have been manufactured and purchased in the absence of the label. While it is likely that Energy Star has spurred manufacturers to innovate and improve the energy efficiency of their products, we cannot necessarily attribute 100 percent of any estimated energy-efficiency benefits to the program itself. Thus, these estimates are best thought of as an upper bound.

The program also might be a best-case scenario in terms of consumer adoption. Because Energy Star products lower carbon emissions by reducing energy consumption, they provide a measurable consumer benefit in the form of less expensive energy bills. While the Energy Star label offers this significant private benefit even without any warm glow or altruism, many other consumer products, such as food and cosmetics, will not. For example, a comparison of frozen versus fresh orange juice finds that frozen juice has a lower carbon footprint due to its lower volume, requiring less transportation and refrigeration space. ${ }^{10}$ To a consumer, price and quality of orange juice likely will be of most interest - and any impact of a carbon footprint label on the type of orange juice consumed most likely will have to come through warm glow, altruism, or other external pressure on orange juice manufacturers or distributors.

Aside from Energy Star, numerous anecdotal industry case studies demonstrate the potential for consumer labels to have a significant effect on products sold in the market. Perhaps the most widely known example is dolphin-safe tuna. Public concern about killing dolphins in the process of catching tuna led to a significant drop in tuna demand. In this case, "dolphin-safe tuna" labels helped to revive the canned tuna market (Teisl and Hicks 2002). Interestingly, part of the shift toward the sale of dolphin-safe tuna apparently came as a result of direct pressure by environmental groups on retailers. Thus, third-party intermediaries may have played as much (if not more) of a role in changing this market as did direct consumer purchase decisions. ${ }^{11}$ This is

\footnotetext{
10 See http://www.carbon-label.com/our-news/case-studies/tesco.

11 See Vandenbergh and Cohen $(2010,276)$ for a discussion of this phenomenon and the evidence in the case of tuna.
} 
consistent with other evidence on the role of third-party nongovernmental pressure on firm environmental behavior (see, e.g., Lenox and Eesley 2009).

A panel study of actual purchase behavior for about 1,600 consumers between 1997 and 2001 in Denmark found that purchasers of toilet paper with a Nordic Swan eco-label had an increased marginal willingness to pay of 13-18 percent (Bjørner et al. 2004). Interestingly, Bjørner et al. found little evidence of a higher willingness to pay for paper towels with the Nordic Swan label. They conjecture this result arises because cloth is an even more environmentally friendly substitute for regular paper towels than the certified ones are, and thus the most environmentally conscious consumers are less likely to buy any paper towels. This example highlights the importance of considering available product substitutions when considering the impact of any future labeling program. It also highlights the fact that consumer purchase decisions might impact the marginal consumer and that analyzing market segments is important to understanding the ultimate impact on consumption patterns.

An experiment in a grocery store in Australia labeled six product categories as having either a "below average," "near average," or "above average" carbon footprint relative to competing brands (Vanclay et al. 2011). Overall, the categories that were below average lost 6 percent of sales, while those that were above average gained 4 percent. However, there was considerable variation depending on price differences. When the green-labeled products were also cheapest, they gained 20 percent of sales following the introduction of the labeling program.

In the United States, there is evidence that a significant percentage of customers are willing to pay a higher price for "green" renewable electricity when given that option on their electricity bills. In 2009, approximately 1.4 million U.S. customers purchased green energy (Bird and Sumner 2010, 7-8). Of these, residential customers purchased 7.2 million megawatts of green electricity, while the nonresidential sector purchased 22.8 million megawatts. While impressive, these figures currently represent less than 1 percent of total electricity consumption in the United States. However, participation varies widely by program. The average utility green pricing program reportedly has about a 2 percent participation rate, but top-performing programs achieved rates ranging from 5.1 percent to 20.8 percent (Bird and Sumner 2010, 9).

Kotchen and Moore (2007) studied participation in two green electricity programs and found that participation is higher with income level, environmental concerns, and altruistic attitudes. Their findings suggest consumer segments and marketing approaches that might increase the uptake of green electricity programs (for example, a joint marketing campaign with environmental and/or charitable organizations). 


\subsection{Consumer Surveys}

In the previous section, we discussed industry and market studies that examine actual purchase behaviors to uncover consumers' willingness to pay for environmental amenities. Researchers have also used surveys to elicit preferences through careful random design. For example, a study by Borchers et al. (2007) provided respondents with several hypothetical bundles of increased electricity costs and green energy sources (solar, wind, biomass, farm methane, and a generic green source), and asked them to choose between these different options or continue current energy sources at no additional cost. They found a positive willingness to pay for green energy, with the highest value being placed on solar energy.

Not all consumer surveys are based on hypothetical purchases. Clark et al. (2003) surveyed consumers who purchased green power (as well as those who did not) in the Detroit, Michigan area. They found that altruism toward the environment was the most significant factor in choosing to purchase green power, followed by altruism toward regional residents and individual health-based concerns. While there was some evidence of warm glow, it was the least important reason. They also found that local health concerns outweighed global concerns.

Although studies have found evidence of altruistic behavior on the part of consumers, any willingness to pay for carbon emission reductions beyond pure energy savings or other personal benefit is still likely to be limited. For example, a recent consumer survey found that 53 percent of respondents claimed that "good corporate behavior" would affect their own purchase behavior only if "price, quality and convenience are equivalent to competing products." In contrast, 30 percent of consumers indicated they would be willing to pay more for a product from a good corporate citizen (Mintel Group 2011, Figure 25). As companies increasingly find more costeffective ways to reduce life-cycle carbon emissions without raising product prices, trade-offs between product prices and carbon emissions are likely to be less important. Indeed, as one corporate executive noted, "Consumers expect products that give brilliant results, at an affordable price, and deliver sustainability benefits-i.e., no trade-offs" (White 2009, 389).

Researchers also have used surveys to examine consumer awareness of environmental labels, finding that awareness varies dramatically by type of label. For example, a 2009 U.S. survey reports that awareness of the Energy Star label is as high as 93 percent, with 73 percent of consumers claiming they are more likely to purchase a product with the label (Ottman 2011, Figure 7.2). In fact, 34 percent of respondents claimed to have purchased energy-efficient electronics or appliances within the past three years (Ottman 2011, Figure 1.3). In contrast, only 
18 percent are aware of the Marine Stewardship Council label for sustainable fish, and only 10 percent claim they would likely base a purchase decision on the label.

Awareness of eco-labels varies significantly by country; yet experience has shown that consumer awareness can grow dramatically in a very short period of time. For example, the Rainforest Alliance reported that consumer awareness of their green frog seal grew from 26 percent to 35 percent between 2009 and 2010 in Germany, and is as high as 54 percent in the United Kingdom and Ireland. ${ }^{12}$

\section{Potential Impact of Carbon Labels}

In this section, we consider the potential impact of carbon labels on aggregate greenhouse gas emissions. As discussed above, there is ample evidence that consumer purchase decisions (whether directly or indirectly through retailer actions) will respond at the margin to credible claims that certain products have environmental benefits over others. However, the question still arises whether carbon labeling can be expected to bring about any meaningful reduction in emissions. We address three of the most widely articulated concerns: leakage outside any labeling scheme, the "rebound" effect, and the potential magnitude of carbon reductions.

\subsection{Leakage}

The concern over leakage has been one of the most widely discussed issues when debating cap-and-trade legislation in the United States and elsewhere. In particular, policymakers are concerned that requiring greenhouse gas emission reductions in their home country will shift production to other countries with less stringent requirements, thereby reducing the impact of any climate legislation. In theory, it is possible that leakage could result in even worse emissions in some cases because the production technologies employed could be dirtier than existing preregulated methods in the home country, and longer transportation distances increase the carbon footprint of bringing these newly imported goods into the home country (Wiedmann et al. 2008). In fact, Watson and Moll (2008) have estimated that leakage and offshoring of production have accounted for virtually all the United Kingdom's reduced carbon emissions from 1990 to 2005, and that if carbon emissions were calculated throughout the supply chain, instead of a 15 percent reduction, the country's emissions actually increased by 19 percent. None of this speaks to the

\footnotetext{
12 See www.rainforest-alliance.org/marketing/why.
} 
more potent political concerns of losing jobs in the home country. Thus, leakage is a very real concern that must be addressed in any serious proposal for greenhouse gas regulation. In the context of greenhouse gas regulations, many of the proposals to deal with leakage involved taxing or subsidizing goods that are traded internationally. ${ }^{13}$

Leakage from a carbon footprint label scheme is also an issue that must be addressed. First, let's consider the direct effect of a carbon footprint label. Presumably, the existence of the label will induce producers to lower their carbon footprint so as to attract consumers who demand this product attribute. If the carbon footprint label is a global standard and is appropriately enforced and complied with, one international trade incentive created by carbon labeling would be to move production from one country to another based on the availability of lower carbon fuel sources or production methods. Even in the absence of a global standard, an alternative approach to reduce carbon leakage is for the home country adopting a labeling requirement to impose its standard on all products sold within its borders (Vandenbergh and Cohen 2010). At the very least, this will reduce the incentive to move production overseas to “dirtier" facilities. It also might provide an incentive for producers in the unregulated country to reduce their greenhouse gas emissions voluntarily in response to increased consumer demand pressures from abroad.

While the direct effects of carbon labeling are clearly in the direction of reducing carbon emissions, consideration of potential feedback effects complicates the picture. For example, Swallow and Sedjo (2000) consider eco-labeling of forest products in a general equilibrium context and show that reduced demand for forestry products possibly will induce the conversion of marginal forestry land to less ecologically desirable agricultural production. Thus, once general equilibrium and cross-product substitution effects are considered, the implications of carbon labeling are not entirely clear.

To take another example, it is possible that labeling the carbon footprint of beef in a developed country could reduce the demand for beef and lower its price sufficiently to induce an increase in the demand for beef in a developing country. The net result might be less carbon reduction than anticipated - or in the worst case, an increase in carbon emissions if beef is now transported internationally more than previously. Thus, careful empirical analysis of the cross-

\footnotetext{
13 See, e.g., Stavins 2008 for a discussion of leakage and Fischer and Fox 2011 for an analysis of alternative proposals to reduce leakage from greenhouse gas regulation.
} 
price elasticity of products and differential price elasticities across countries (or even consumer segments within a country), industry structure, and alternative uses of production inputs is warranted before definitive policy recommendations can be made.

Although unilateral action by one country might bring about reductions in the carbon footprint of its home country consumers, the absence of a global standard brings with it new complications. In particular, unilateral action of this nature raises the potential of trade wars. It also highlights the importance of an objective and standard methodology that is not designed to aid one country's products over another. These issues are addressed in Section 5.

\subsection{Rebound Effect versus Increasing Social Norm for Carbon Reductions}

In addition to "leakage" across countries, concern has been expressed that individual consumers might offset their own green purchasing decisions by reducing their environmentally friendly behavior in another dimension of their lives. One can construct a rational utilitymaximizing model of consumer behavior whereby lowering the search costs through carbon footprint labels provides new information to consumers that allows them to rebalance their mix of low-carbon and high-carbon products. For example, it is possible that a consumer who currently purchases "green power" through their electricity provider will now feel better about her use of electricity and will increase usage, partially (or even fully) offsetting the emissions reductions from purchasing green power. Alternatively, a green power purchaser who learns about a newly instituted carbon-labeling scheme might reduce her green power consumption and use that savings to purchase a low-carbon consumer product that costs a little more than the consumer product she used to buy. This consumer will ultimately be better off from carbon labeling, but her carbon footprint might remain unchanged. These are examples of what has been termed the "rebound effect."

The evidence to date suggests that while there is some offsetting behavior, it is unlikely to offset carbon reductions in any meaningful way. For example, Jacobsen et al. (forthcoming) studied electricity consumption for consumers in Memphis, Tennessee, some of whom had purchased green power at a premium price. In the aggregate, they found no statistically significant difference in energy consumption following purchase of green energy. However, households at the minimum level of green energy participation did increase their electricity consumption by approximately 2.5 percent after enrolling in the program. Even for these consumers, however, the net effect on carbon emissions was actually negative because any increase in emissions due to their increased consumption was more than outweighed by the reduced emissions from their green energy purchase. 
While the Jacobsen et al. results suggest only minimal offsetting behavior - and a significant positive impact on energy consumption (and a net decrease in emissions) — we do not know if the green power consumers increased or decreased their consumption of other products with a carbon footprint. On the one hand, it is possible that some of these consumers increased their consumption of other "dirty" products upon deciding to purchase green power. On the other hand, it is quite possible that the effect would go the other way-heightened awareness and habits of purchasing carbon-friendly products might increase consumer propensity to reduce their carbon footprint elsewhere in their life choices. While there is little or no evidence on this effect in the context of greenhouse gas emissions, one study of Danish consumers over a threeyear period found that heavy recyclers tended to increase their purchase of organic foods, although the researchers observed some potentially offsetting behavior (Thøgersen and Ölander 2003). This remains an important topic for future research.

\subsection{Can Consumer Product Labeling Really Have an Impact?}

The production, transport, and consumption of consumer goods accounts for a substantial share of U.S. and global greenhouse gas emissions, suggesting that small changes in consumption may have important effects on domestic and global emissions. In 2005, direct energy use by U.S. households accounted for approximately 38 percent of overall U.S. carbon dioxide $\left(\mathrm{CO}_{2}\right)$ emissions, or 626 million metric tons of carbon (Gardner and Stern 2008; Energy Information Agency 2008). The total from household energy use represents approximately 8 percent of global emissions, an amount that is larger than the total emissions of any country other than China (Dietz et al. 2009; Vandenbergh and Steinemann 2007). Consumer goods potentially subject to carbon labeling account for much of the energy use and emissions from the U.S. household sector (Dietz et al. 2009, Table 1).

To the extent carbon labeling reduces leakage arising from international trade, it has the potential to affect a large share of global greenhouse gas emissions. One study concluded that leakage from the United States exceeded 20 percent of global warming potential in 2004 (Ghertner and Fripp 2007). A consumption-based model concluded that goods and services traded internationally accounted for 23 percent of global $\mathrm{CO}_{2}$ emissions in 2004 (Davis and Caldeira 2010), and the share attributable to internationally traded goods and services appears to be increasing. For example, Peters et al. (2011) concluded that emissions from the production of internationally traded goods increased from 20 percent of global $\mathrm{CO}_{2}$ emissions in 1990 to 26 percent in 2008 . 
The growing recognition of the importance of emissions embodied in trade has generated calls for shifting national emissions inventory accounting from an exclusive focus on emissions within national boundaries toward a consumption-based approach (Peters and Hertwich 2008).

\section{Practical Issues}

The goal of carbon footprint labels is to provide businesses and consumers with meaningful information that will ultimately allow them to make informed decisions about product choice, use, or both. To achieve that goal, numerous practical issues must be overcome. This section briefly reviews some of the major methodological concerns, international trade issues, and design issues associated with carbon labeling. Critics, including some environmentalists, claim that these challenges make carbon labeling misleading and potentially unable to change consumer behavior. ${ }^{14}$ While these concerns are potentially valid, the key question is whether carbon footprint methodologies and standards can be developed to minimize these issues - and at what cost?

\subsection{Methodological Challenges}

The methodological challenges to implementing a reliable carbon-labeling program are significant. Measuring and verifying the carbon emissions of a product's life cycle involves numerous assumptions and compromises. For example, a product might be manufactured at several different facilities, each using different energy sources and having different paths of shipment to their final destination. Thus, two identical products might have different manufacturing carbon footprints. At the other end of the life cycle, consumers differ in how they use and dispose of the product.

Koning et al. (2009) provide an example of the uncertainties associated with comparing the carbon footprint of ultra-liquid versus compact powder laundry detergent. In their example, they show how increasing the discretion allowed for the choice of life-cycle model parameters can result in misleading results. For example, when key assumptions, such as end-user washingmachine efficiency, temperature selection, and electricity sources, are standardized, ultra-liquid detergent results in a lower carbon footprint 100 percent of the time. When most of these

\footnotetext{
${ }^{14}$ For example, see Julia Hailes, "Carbon Footprint and Carbon Labeling," http://www.juliahailes.com/pdfs/CarbonFootprint-PrintedVersion.pdf.
} 
parameters are allowed to vary, however, the compact powder detergent is estimated to have a lower carbon footprint 23 percent of the time.

The methodological issues associated with carbon footprint labeling give rise to numerous policy challenges. On a practical level, they highlight the importance of adopting a single, globally recognized protocol for standardized carbon footprint methodologies. Two organizations have developed such life-cycle protocols using similar principles and a multistakeholder approach. These protocols are the British Standards Institute's (2011) Publicly Available Specification 2050 and the Greenhouse Gas Protocol's (2011) Product Life Cycle Accounting and Reporting Standard. The International Standardization Organization also is developing a carbon-labeling standard, ISO 14067, expected to be finalized within the next year or two. ${ }^{15}$

According to the Greenhouse Gas Protocol, the two existing standards are very similar and unlikely to result in significant differences in their measurement outcomes. Both provide principles on how to develop transparent life-cycle measures for products. However, they are not detailed enough to provide aggregation rules or sector-specific assumptions. Instead, further work at the sector (and even product category) level is needed to arrive at consistent, comparable carbon footprint labels.

Even if a standardized methodology is adopted, however, discrepancies inevitably will arise between the carbon footprint label and the emissions realized by one consumer (or class of consumers). For example, the extent to which an all-electric vehicle produces fewer greenhouse gases than a high-efficiency gasoline-powered vehicle depends greatly on the electricity fuel mix, which can include low- or high-efficiency coal-fired power plants, natural gas-powered electricity, renewable energy sources, and the like. ${ }^{16}$ Depending on the frequency and magnitude of this discrepancy, one can envision various possible solutions:

- do nothing (i.e., maintain one carbon footprint label);

\footnotetext{
15 The Greenhouse Gas Protocol is a cooperative initiative of the World Resources Institute and the World Business Council for Sustainable Development. The ISO 14067 standards are being developed in collaboration with both organizations. See "Quantifying the Greenhouse Gas Emissions of Products: PAS 2050 \& the GHG Protocol Product Standard," http://www.ghgprotocol.org/standards/product-standard.

16 This point has been made in the case of China's recent push to adopt electric vehicles. In many parts of the country, there might be little or no carbon benefit from an electric vehicle under current electricity generation technologies (Earley et al. 2011).
} 
- prepare different labels depending on the local source of electricity;

- develop a more complex label that provides multiple values that depend on the local source of electricity; or

- determine that the high degree of variability and lack of clear superiority among products are such that carbon labels for this product category should not be a priority.

\subsection{Trade Issues}

The international trade regime poses a potential barrier to some types of product carbonlabeling systems. The World Trade Organization (WTO) oversees a complex set of rules that are designed to strike a balance between the right of WTO members to advance legitimate goals, including environmental protection, and the right of other members not to have such measures applied arbitrarily or serve as a form of disguised protectionism (Dunoff 1994). Two international trade agreements may serve as barriers to a carbon-labeling system: the General Agreement on Tariffs and Trade (GATT) and the Agreement on Technical Barriers to Trade (TBT Agreement). A carbon-labeling program may take the form of a mandatory public system, voluntary public system, or voluntary private system, and the vulnerability to a trade challenge under these treaties likely declines in that order.

In general, the GATT prohibits discrimination against the import of "like products." For example, import laws cannot discriminate in favor of domestic goods over "like products" from other nations. Jurisprudence developed in some trade disputes typically defines "like products" in terms of the physical characteristics of goods as opposed to the process and production methods ("PPMs") used in the harvesting, processing, manufacture or production of the goods (Vranes 2011; Kysar 2004). This focus on the physical characteristics of the good rather than PPMs may induce the trade regime to view a good with very different provenance from another to be a "like product" (e.g., GATT Arts. I(1) and III(4)). A life-cycle analysis-based government carbon-labeling system thus may be vulnerable to a claim that it is a PPM measure that discriminates against "like products," even though the products have different carbon footprints. Under Article III of the GATT, regulatory measures that treat like products differently based on non-product-related PPM issues (often referred to as "npr-PPMs" or "unincorporated PPMs") may be viewed as discriminatory even if the measures are neutral as to country of origin (Joshi 2004).

The npr-PPM measures, if deemed discriminatory and a violation of the GATT, may nonetheless meet one of the exceptions provided in GATT Article XX (Vranes 2011; Pauwelyn 
2004; Charnovitz 2002). Provided that the measures "are not applied in a manner which would constitute a means of arbitrary or unjustifiable discrimination ... or a disguised restriction on international trade," Article XX permits measures are otherwise illegal if they are "necessary to protect human, animal or plant life or health" or, a somewhat less stringent test, "relating to the conservation of exhaustible natural resources if such measures are made effective in conjunction with [similar domestic measures]." ${ }^{17}$ But there is very little law on labeling or other climaterelated questions, and whether WTO dispute bodies would construe Article XX to permit carbonlabeling systems is unclear (Brazil-Tyres; United States_-Shrimp/Turtle I).

The possibility that a discriminatory trade restriction will be deemed exempt, and thus survive a trade challenge, diminishes in situations where the environmental effects concern another country's environmental quality or resources, or where the basis of the restricting country's concern about global environmental resources is viewed as illegitimate. For example, Mexico challenged U.S. dolphin-safe labeling restrictions in part by asserting that they did not fulfill a legitimate objective (United States-Tuna/Dolphin II). If there is an adequate nexus between resources in each of the countries involved (e.g., turtles that move between the waters of the nation adopting the trade restriction and the restricted nation (United States-Shrimp/Turtle I and II)), or if the environmental concern is a matter of endangerment covered by an international treaty (e.g., sea turtles in United States-Shrimp/Turtle I and the Convention on International Trade in Endangered Species), the trade restriction may be upheld.

It is not clear how these issues will be addressed for an npr-PPM that has a global or universal impact, such as a carbon-labeling system. Carbon emissions externalize harm in ways that may affect the restricted country and the country adopting the carbon-labeling measure, and they may affect not just abstract environmental concerns but physical environmental conditions. Carbon emissions in China arising from a good produced for a Danish consumer are likely to affect Denmark as well as China, and the potential harms arising from changes in climate and sea level in both countries are more concrete than concerns about global dolphin populations. The existence of the Framework Convention on Climate Change and its Kyoto Protocol, whose purpose is to reduce and restrain carbon emissions to avoid such potential harms, may buttress this point with policymakers.

\footnotetext{
17 The Shrimp/Turtle II ruling makes it clear that process-based measures may fall within the scope of the general exceptions clause (United States-Shrimp/Turtle II).
} 
A WTO dispute settlement panel may evaluate a TBT Agreement claim before turning to a GATT claim (EC-Asbestos; United States-Tuna/Dolphin II). ${ }^{18}$ The TBT Agreement extends to all technical regulations, standards, and conformity assessment procedures that apply to trade in goods. Under the TBT Agreement, a labeling system determined to be a "technical regulation" must be neither discriminatory nor "more trade-restrictive than necessary" to fulfill a legitimate objective and should be based on an international standard, if one exists (TBT Agreement 2.1, 2.2). ${ }^{19}$ Prior panel decisions suggest that the WTO takes a broad view of both "technical regulations" and "more trade-restrictive than necessary" (EC-Sardines; United StatesTuna/Dolphin II). Although technical regulations that are related to the product clearly fall within the scope of the TBT Agreement, substantial disagreement exists over whether technical regulations are subject to the agreement if they are not related to the product's characteristics (Vranes 2011; Joshi 2004). In addition, in the 2011 Tuna/Dolphin case, Mexico claimed that the labeling provisions were tantamount to a ban on the sale of non-dolphin-safe tuna in the United States. A label that merely provides information (e.g., a carbon footprint score) may not be viewed in the same light as the dolphin-safe label requirements. A number of current government-sponsored eco-label programs provide PPM information, and the WTO's Committee on Trade and Environment has been studying eco-labels for over a decade without taking a stand on these labels.

Uncertainty also exists on the extent to which government product-labeling programs, as opposed to other types of government regulatory measures, are vulnerable to trade challenges (United States-Tuna/Dolphin I). The TBT Agreement explicitly distinguishes between technical regulations (with which compliance is mandatory) and technical standards (which are voluntary), but both are potentially subject to challenge. Programs are treated as mandatory if the label is a legally binding market-access requirement (Tietje 1995), and an expansive view has

\footnotetext{
${ }^{18}$ For example, the 2011 Tuna/Dolphin ruling found the United States in violation of TBT 2.2 and declined to rule on the GATT claims (United States-Tuna/Dolphin II).

${ }^{19}$ For example, U.S. dolphin safe tuna labeling was determined to be more trade restrictive than necessary because the "labeling provisions only partly address the legitimate objectives pursued," and Mexico, the complaining Member, provided the WTO dispute panel with a less trade-restrictive alternative capable of achieving the same level of protection as the objective pursued by the original measure (United States-Tuna/Dolphin II).
} 
been taken about when a measure is mandatory (United States - Tuna/Dolphin II). ${ }^{20}$ Government consumer product labels are more likely to be viewed as WTO-compliant when they are voluntary, participatory, market-based, and transparent (Committee on Trade and the Environment 2003), but the 2011 Tuna/Dolphin decision suggests that the definition of "mandatory" may be viewed broadly, and the status of even voluntary government-administered npr-PPM measures under the TBT Agreement is hotly debated (Vranes 2011; Joshi 2004).

In addition, the approach of the trade regime to private carbon-labeling systems may differ from the approach to government systems. A robust literature and several WTO dispute reports exist on mandatory and voluntary government environmental measures, but many ecolabeling programs are developed and administered by nongovernmental organizations and private firms. The trade implications of these private programs, which may have little or no governmental involvement, have been studied less exhaustively, but there are reasons to believe that they are less vulnerable to a WTO challenge. ${ }^{21}$

Although only states can be parties to WTO disputes, a private organization's labeling program can give rise to a WTO dispute. First, the TBT Agreement obliges WTO members to take "all reasonable measures" to ensure that private standardizing bodies adhere to a Code of Good Practice found in an annex to the TBT Agreement. Moreover, acts by private parties can give rise to disputes when these acts are "attributable to a WTO member." ${ }^{22}$ The boundaries of what is attributable to a WTO member are unclear, but one WTO panel determined that private actions with "sufficient government involvement" may be attributed to a WTO Member (Japan-Film, If 10.52). The panel declined to elaborate on the definition of sufficient government involvement, ${ }^{23}$ but some combination of actions, such as government funding of the

\footnotetext{
${ }^{20}$ For example, the 2011 Tuna/Dolphin panel decision on Mexico's challenge was to a U.S. law that did not require labeling of tuna as dolphin-safe but set standards that had to be met if a label was used. The panel concluded that "the measures at issue establish labeling requirements, compliance with which is mandatory" (United StatesTuna/Dolphin II).

21 The WTO dispute resolution mechanism under the Understanding on Rules and Procedures Governing the Settlement of Disputes asserts jurisdiction over disputes between WTO Members arising under agreements covered in Article 1.1 understanding.

${ }^{22}$ See, e.g., United States-Hot-Rolled Steel, II 81, which concludes that “[i]n principle, any act or omission attributable to a WTO Member can be a measure of that Member for purposes of dispute settlement proceedings."

23 Actions "taken by private parties does not rule out the possibility that it may be deemed to be governmental if there is sufficient government involvement with it. It is difficult to establish bright-line rules in this regard, however. Thus, that possibility will need to be examined on a case-by-case basis" (Japan-Film).
} 
standard development or implementation, government approval of the standard or the participants in the standard setting, or inclusion of the standard in procurement, ${ }^{24}$ could raise concerns (e.g., Argentina-Leather; Canada-Dairy; EC-Apples; Japan-Film). In short, although mandatory and voluntary government labeling programs may avoid or survive a WTO challenge, a private approach with limited government involvement may be the least vulnerable (Vandenbergh et al. 2010).

The ultimate effects of the trade regime on carbon labeling also may be influenced by how these issues are framed in the broader policy context. Carbon labeling can be framed in policy debates as frustrating free trade, economic opportunity, and the sovereignty of the producing (often developing) country, ${ }^{25}$ or as promoting the freedom of individuals in the consuming (often developed) country to have access to information that will enable them to express preferences for reducing the likelihood of climate change through less carbon-intensive consumption (Vandenbergh and Cohen 2010). In the absence of trade disputes over carbon labeling systems, it is too early to tell how these issues will arise and whether they will affect the treatment of government and private carbon-labeling systems by the trade regime.

\subsection{Product Label Design Issues}

Although carbon labels are relatively new, product labels have a long history dating back to the 1960s in the United States. Both government-mandated and voluntary third-party certified labels now exist for a host of products and attributes ranging from cigarettes, nutritional content of food, organic produce, flammable materials, and hazardous chemicals. Beginning with Viscusi and Magat (1987), many studies have focused on consumer responses to labels with the goal of designing meaningful communication vehicles that will not mislead and will provide actionable information. A recent paper by Cohen and Viscusi (forthcoming) summarizes this

\footnotetext{
24 The extent to which government procurement policies are subject to review under the TBT, Article 1.4, is unclear, as is the extent to which procurement policies might affect whether a dispute panel would take jurisdiction over a private carbon label. Procurement policies are reviewed under the Agreement on Government Procurement, which is one of the "plurilateral agreements" within the WTO structure. As such, the GPA is binding only on those WTO members who choose to adhere to it, unlike the GATT and TBT, which are binding upon all WTO members.

${ }^{25}$ See, e.g., United States - Gasoline, which concludes that "WTO Members have a large measure of autonomy to determine their own policies on the environment (including its relationship with trade), their environmental objectives and the environmental legislation they enact and implement. So far as concerns the WTO, that autonomy is circumscribed only by the need to respect the requirements of the General Agreement and the other covered agreements."
} 
literature and makes recommendations related to carbon footprint labels. Many of these recommendations involve the design of labels to ensure that consumers "receive, process, believe and use" the information on them.

Label design issues are largely outside the scope of this paper. However, we note that in addition to affecting consumer behavior, labels have the potential of affecting firm behavior in product design, manufacturing, and marketing. For example, a numerical score is generally superior to a threshold label (e.g., Energy Star) because it provides appropriate incentives for continuous improvement (Cohen and Viscusi). However, on a practical level, one must consider the feasibility of numerical labels, especially given the uncertainty and range of life-cycle carbon emissions estimated for many products.

One critical issue that arises in the context of our analysis is how to ensure that the product label not only conveys static information about the product life cycle but also provides actionable information to consumers when their product use decisions have a significant impact on carbon emissions. For example, life-cycle assessments have determined that water temperature is the most significant factor in carbon emissions resulting from home laundry activities (White 2009), yet consumers often use warmer water than called for on the product instructions. Thus, in attempting to reduce their product life-cycle carbon emissions, Proctor $\&$ Gamble focused their attention on an education campaign to convince U.K. consumers to use cold water. This example raises two interesting questions from a carbon-labeling perspective. First, should the carbon footprint be calculated based on actual consumer use or on the instructions that call for cold water? Note that Publicly Available Specification 2050 resolves this issue by calling for "actual usage" to be the guiding principle (British Standards Institution 2011, Section 6.4.9.2). Second, how can the label be used to help educate consumers about the proper product use and to provide firms with the incentive to change consumers' "actual usage" over time? The answer to this question might require significant market research and testing in the product label design phase.

An important caveat to our analysis of carbon labels is that many of the existing product labels are based on multiattribute criteria, and terms such as "eco-labels" or "sustainability" are used to convey their benefits. For example, the Green Seal certification process ${ }^{26}$ includes product ingredients (toxics, carcinogens, etc.), worker safety, human rights, water pollution, and

\footnotetext{
${ }^{26}$ See (www.greenseal.org).
} 
greenhouse gas emissions (among other issues). A separate carbon footprint label might confuse consumers and/or crowd out labels that focus on other social issues. While this is not an inevitable outcome, care must be taken not to impose excessive costs on other product attribute labels that serve important social roles.

\subsection{Which Products Should Be Labeled?}

Labeling the carbon emissions associated with millions of consumer goods would be expensive, and the marginal costs of labeling will exceed the benefits for many goods. Critics of carbon labeling have noted that labeling in itself is not a comprehensive remedy for carbon emissions, some goods within a product category have only minor differences in carbon emissions, other goods do not have low-carbon substitutes, and many goods have complex or variable supply chains that will require high transaction costs to assess. ${ }^{27}$ All these concerns are sound, and a carbon-labeling system, particularly a private one, is unlikely to be widely adopted and achieve substantial carbon emissions reductions unless a subset of the most promising goods can be identified.

The challenge is to identify those goods that will yield significant emissions reductions at comparatively lower cost than other near-term options. A carbon-labeling system should be compared not with ideal alternative instruments but with the viable options for the relevant time period. ${ }^{28}$ With the current international deadlock, a carbon tax or cap-and-trade system offers only limited near-term competition to a carbon-labeling regime. Meanwhile, a carbon-labeling system may be able to circumvent the collective action problems that these international and domestic public measures face, generate near-term emissions reductions to buy time for more comprehensive remedies, build public support for the more comprehensive remedies, and provide supply chain information that will facilitate the implementation of anti-leakage provisions in the more comprehensive remedies (Vandenbergh et al. 2011). For example, a successful U.S. cap-and-trade program will require some form of border allowance system, which presumes the ability to gather and analyze many of the types of carbon emissions data for consumer goods that will be developed through carbon labeling.

\footnotetext{
27 For example, see “Carbon Footprints: Following the Footprint," Economist, June 2, 2011.

${ }^{28}$ Dan Farber (2012) calls the tendency to dismiss good proposals based on the existence of conceivable but nonviable alternatives the "fallacy of the hypothetical alternative."
} 
Here, we begin to sketch out principles for determining which goods are best suited for carbon labels. The first is that the screening methodology must identify goods for which changes in consumption (whether substitution or reduced use) yield large carbon emissions reductions. Although this is a commonsense concept on the surface, a variety of influences easily can distract attention from this goal, and the history of measures focused on consumer and household energy use and environmental impacts includes numerous examples of efforts directed at actions that either have low technical potential or are unlikely to be adopted by consumers (Dietz et al. 2009).

A second principle is that the screening methodology must be able to account for the costs of information gathering. As discussed above, the complexity of the issues at each of the important stages in the life cycle of a product suggests that a system that seeks a high degree of precision will collapse under the weight of heavy transaction costs. Goods with more complex or shifting supply chains, for example, may not be promising initial candidates for carbon labeling. For many goods, however, the error bands may not overlap: limited information may result in a wide range of potential emissions that are attributable to the good, but even the high-end carbon emissions estimate of a substitute good is unlikely to be as high as the low end of the other (e.g., chicken versus beef).

A third principle is that the screening for the most promising products should account for each step in the life cycle of a good, including production, transport, storage and sales, consumption, and disposal. However, it may not be necessary to conduct a detailed analysis of all aspects of any one step in the life cycle of a good. For example, it may be possible to screen for transport emissions for some goods based on the distance traveled. For other goods, the carbon intensity of the means of transport may account for a sufficiently large share of total emissions to serve as a screening criterion. For some agricultural products, seasonality may have such a large effect on the carbon footprint of a category of goods that screening criteria can be developed to identify categories of the most promising goods. One example is field-grown tomatoes in the summer versus hothouse tomatoes in the winter in England.

A fourth principle is that the screening methodology should account for the behavioral plasticity of consumers - i.e. the extent to which behavior is likely to change following a new policy (in this case, introduction of a carbon label). ${ }^{29}$ Goods differ both in the extent to which

\footnotetext{
29 York et al. (2002) proposed the term "behavioral plasticity" to describe this phenomenon in the household behavior context.
} 
labels are likely to affect consumer purchasing decisions (Golden 2010, 11$)^{30}$ and the substitutes that consumers are likely to select when changing consumption patterns. The elasticity of demand and carbon footprints of likely substitutes are known for many consumer goods (e.g., Okrent and Alston 2011) and can be estimated for others.

For a voluntary government or private system, an important fifth principle is that the screening of goods for labeling should account for those goods that firms may have the greatest incentive to label (i.e., the behavioral plasticity of the firm). For instance, if a good will be subject to reputation campaigns or boycotts, the firm selling it has an incentive to participate in a labeling system (Lenox and Eesley 2009). Similarly, a good is amenable to labeling if carbonfriendly changes to the supply chain or substitution opportunities among the firm's goods will lead to energy cost savings (Humes 2011; Carbon Trust 2006 11, 13).

\section{Concluding Remarks}

Carbon footprint product labeling is in its infancy as companies, third-party certification organizations, and government agencies experiment with methodology and label design. While we are already beginning to see an emerging global standardized protocol for estimating the lifecycle carbon footprint of products, no such standardized approach to labeling has yet emerged.

The theory behind carbon footprint labeling is clear: without information about the greenhouse gas implications of product choices, consumers are unable to make informed choices about which products to purchase and how to use them. However, the theory is also clear that without credible third-party certification, it is unlikely that a meaningful carbon-labeling market will develop. Moreover, because climate change is a global problem and international trade accounts for a significant portion of carbon emissions, any meaningful carbon-labeling system will require a globally accepted, uniform methodology for calculating life-cycle emissions and labeling products.

The empirical evidence on the potential impact of carbon labeling is sparse but growing. Some product segments have a large potential for carbon emission reductions, and significant

\footnotetext{
30 Golden notes, "Ecolabels do not impact purchasing decisions equally across product categories. Four variables in particular determine consumption practices when it comes to buying green: purchase visibility, consumption visibility, durability, and perishability. Ecolabels matter more for nondurable, frequently used, and highly visible consumer goods. So, being an environmentally responsible soft drink producer should carry more of a competitive advantage than being an ecofriendly insulation manufacturer."
} 
consumer segments care about carbon emissions. The latter are likely to grow as more information is disclosed and as life-cycle analyses uncover more ways to reduce carbon emissions without increasing — or even while decreasing - the cost to consumers. Perhaps as important, we expect carbon labeling to have a role in increased supply chain pressures by manufacturers and large chain stores to reduce the carbon emissions of products they carry.

While the methodological and legal challenges to the establishment of effective carbonlabeling programs are significant, careful analysis and selection of product categories to be labeled could ultimately bring about significant reductions in carbon emissions in a manner that is cost-effective and consistent with international trade standards. 


\section{References}

Agreement on Government Procurement, April 15 1994, Marrakesh Agreement Establishing the World Trade Organizations, Annex 4(b), 33 I.L.M. 1125.

Andreoni, J. 1990. Impure Altruism and Donations to Public Goods: A Theory of Warm-Glow Giving. Economic Journal 100: 464-477.

Argentina-Leather. Panel Report, Argentina-Measures Affecting the Export of Bovine Hides and the Import of Finished Leather, WT/DS155/R (December 19, 2000).

Baksi, S., and P. Bose. 2007. Credence Goods, Efficient Labeling Policies, and Regulatory Enforcement. Environmental and Resource Economics 37(2): 411-30.

Baron, D.P., and D. Diermeier. 2007. Strategic Activism and Nonmarket Strategy. Journal of Economics \& Management Strategy 16(3): 599-34.

Bird, L., and J. Sumner. 2010. Green Power Marketing in the United States: A Status Report. Technical Report NREL/TP-6A20-4903. Washington, DC: National Renewable Energy Laboratory. http://www.nrel.gov/docs/fy11osti/49403.pdf.

Bjørner, T.B., L.H. Lars Gårn, and C.S. Russell. 2004. Environmental Labeling and Consumers' Choice-An Empirical Analysis of the Effect of the Nordic Swan. Journal of Environmental Economics and Management 47(3): 411-34.

Borchers, A.M., J.M. Duke, and G.R. Parsons. 2007. Does Willingness to Pay for Green Energy Differ by Source? Energy Policy 35(6): 3327-3334.

Brazil-Tyres. Appellate Body Report, Brazil-Measures Affecting Imports of Retreaded Tyres, WT/DS332/AB/R (December 3, 2007).

British Standards Institution. 2011. PAS 2050: 2011-Specification for the Assessment of the Life Cycle Greenhouse Gas Emissions of Goods and Services. London. http://www.bsigroup.com/upload/Standards\%20\&\%20Publications/Energy/PAS2050.pdf.

Brown, R., C. Webber, and J. Koomey. 2002. Status and Future Directions of the ENERGY STAR Program. Energy 27(5): 505-20.

Canada-Dairy. Appellate Body Report, Canada-Measures Affecting the Importation of Milk and the Exportation of Dairy Products, WT/DS103/AB/R, WT/DS113/AB/R (Oct. 13, 1999). 
Carbon Trust. 2006. Carbon Footprints in the Supply Chain: The Next Stop for Business. Publication ID CTC616. London.

Clark, C.F., M.J. Kotchen, and M.R. Moore. 2003. Internal and External Influences on ProEnvironmental Behavior: Participation in a Green Electricity Program. Journal of Environmental Psychology 23(3): 237-246.

Charnovitz, S. 2002. The Law of Environmental "PPMs" in the WTO: Debunking the Myth of Illegality. Yale Journal of International Law 27(1): 59-110.

Committee on Trade and the Environment, Report to the 5th Session of the Ministerial Conference in Cancun - Paragraphs 32 and 33 of the Doha Ministerial Declaration, para. 30, WT/CTE/8 (July 11, 2003).

Cohen, M., and W.K. Viscusi. Forthcoming. The role of information disclosure in climate mitigation policy. Climate Change Economics.

Convention on International Trade in Endangered Species of Wild Fauna and Flora, March 3, 1973, 27 U.S.T. 1087, T.I-A.S. No. 8249, 993 U.N.T.S. 243.

Davis, S.J., and K. Caldeira. 2010. Consumption-based Accounting of $\mathrm{CO}_{2}$ Emissions. Proceedings of the National Academy of Sciences 107(12): 5687-93.

Darby, M.R., and E. Karni. 1973. Free Competition and the Optimal Amount of Fraud. Journal of Law and Economics 16(1): 67-8.

Dietz, T., G.T. Gardner, J. Gilligan, P.C. Stern, and M.P. Vandenbergh. 2009. Household Action Can Provide a Behavioral Wedge to Rapidly Reduce U.S. Carbon Emissions. Proceedings of the National Academy of Sciences 106(44): 18452-56.

Dranove, D., and G.Z. Jin. 2010. Quality Disclosure and Certification: Theory and Practice. Journal of Economic Literature 48(4): 935-63.

Dunoff, J. 1994. Institutional Misfits: The GATT, The ICJ \& Trade-Environment Disputes. Michigan Journal of International Law 15: 1043-1128.

Earley, R., L. Kang., F. An, L. Green-Weiskel. 2011. Electric Vehicles in the Context of Sustainable Development in China. Commission on Sustainable Development. Background Paper No. 9. CSD19/2011/BP9. New York: United Nations Department of Economic and Social Affairs. http://www.un.org/esa/dsd/resources/res_pdfs/csd19/Background-Paper-9-China.pdf. 
EC-Asbestos. Appellate Body Report, European Communities-Measures Affecting Asbestos and Asbestos-containing Products, WT/DS135/AB/R (March 12, 2001).

EC-Sardines. Appellate Body Report, European Communities-Trade Description of Sardines, WT/DS231/AB/R (September 26, 2002).

Energy Information Administration. 2008. Emissions of Greenhouse Gases in the United States 2007. Washington, DC: U.S. Department of Energy.

Farber, D.A. 2012. Climate Justice. Michigan Law Review 100: 985-1002.

Fischer, C., and A.K. Fox. 2011. The Role of Trade and Competitiveness Measures in US Climate Policy. American Economic Review: Papers \& Proceedings 101(3): 258-62.

Gardner G.T., and P.C. Stern. 2008. The Short List: The Most Effective Actions U.S. Households Can Take to Curb Climate Change. Environment 50(5): 12-23.

General Agreement on Tariffs and Trade, October 30, 1947, 61 Stat. A-11, 55 U.N.T.S. 194.

Ghertner, D.A., and M. Fripp, 2007. Trading Away Damage: Quantifying Environmental Leakage through Consumption-Based, Life-Cycle Analysis. Ecological Economics 63(23): 563-577.

Golden, J.S., ed. 2010. An Overview of Ecolabels and Sustainability Certifications in the Global Marketplace. Interim Report Document \#1010-10-1. Durham, NC: Nicholas Institute, Duke University. $\underline{\text { http://center.sustainability.duke.edu/sites/default/files/documents/ecolabelsreport.pdf }}$

Greenhouse Gas Protocol. 2011. Product Life Cycle Accounting and Reporting Standard. Washington, DC: World Resources Institute and World Business Council for Sustainable Development. http://www.ghgprotocol.org/standards/product-standard.

Grossman, S. 1981. The Informational Role of Warranties and Private Disclosure about Product Quality. Journal of Law and Economics 24(3): 461-89.

Humes, E. 2011. Force of Nature: The Unlikely Story of Wal-Mart's Green Revolution. New York: HarperCollins.

Ibanez, L., and G. Grolleau. 2008. Can Ecolabeling Schemes Preserve the Environment? Environmental and Resource Economics 40(2): 233-49.

Ippolito, P.M., and A.D. Mathios. 1990. The Regulation of Science-based Claims in Advertising. Journal of Consumer Policy 13(4): 413-45. 
Jacobsen, G., M.J. Kotchen, and M.P. Vandenbergh. Forthcoming. The Behavioral Response to Voluntary Provision of an Environmental Public Good: Evidence from Residential Electricity Demand. European Economic Review. http://environment.yale.edu/kotchen/pubs/response.pdf.

Japan-Film. Panel Report, Japan-Measures Affecting Consumer Photographic Film and Paper, 10.56, WT/DS44/R (March 31, 1998).TBT Agreement (Agreement on Technical Barriers to Trade), April 15, 1994, Marrakesh Agreement Establishing the World Trade Organization, Annex 1A, 1868 U.N.T.S. 120.

Joshi, M. 2004. Are Eco-labels Consistent with World Trade Organization Agreements? Journal of World Trade 38(1): 69-92.

Kals, E., D. Schumacher, and L. Montada. 1999. Emotional Affinity toward Nature as a Motivational Basis to Protect Nature. Environment \& Behavior 31(2): 178-202.

Koning, A., Schowanek, D., Dewaele, J., Weisbrod, A., and Guinee, J. 2009. Uncertainties in a Carbon Footprint Model for Detergents; Quantifying the Confidence in a Comparative Result. International Journal of Life Cycle Assessment; DOI 10.1007/s11367-009-01233.

Kotchen, M.J. 2006. Green Markets and Private Provision of Public Goods. Journal of Political Economy 114(4): 816-34.

Kotchen, M.J. 2005. Impure Public Goods and the Comparative Statics of Environmentally Friendly Consumption. Journal of Environmental Economics and Management 49(2): 281-300.

Kotchen, M.J., and M.R. Moore. 2007. Private Provision of Environmental Public Goods: Household Participation in Green-electricity Programs. Journal of Environmental Economics \& Management 53(1): 1-16.

Kysar, D. 2004. Preferences for Processes: The Process/Product Distinction and the Regulation of Consumer Choice. Harvard Law Review 118(2): 525-642.

Lenox, M.J., and C.E. Eesley. 2009. Private Environmental Activism and the Selection and Response of Firm Targets. Journal of Economics and Management Strategy 18(1): 4573.

Lyon, T.P., and J.W. Maxwell. 2011. Greenwash: Corporate Environmental Disclosure under Threat of Audit. Journal of Economics and Management Strategy 20(1): 3-41. 
Maiteny, P.T. 2002. Mind in the Gap: Summary of Research Exploring "Inner" Influences on Pro-sustainability Learning and Behaviour. Environmental Education Research 8(3): 299-306.

Mintel Group. 2011. Green Marketing-U.S.-April 2011.

Nelson, P. 1970. Information and Consumer Behaviour. Journal of Political Economy 78(2): 311-29.

Okrent, A.M., and J.M. Alston. 2011. The Demand for Food in the United States: A review of the Literature, Evaluation of Previous Estimates, and Presentation of New Estimates of Demand. Monograph 48. Berkeley, CA: Giannini Foundation of Agricultural Economics. http://giannini.ucop.edu/Monographs/48-FoodDemand.pdf

Ottman, J. 2011. The New Rules of Green Marketing. San Francisco: Barrett-Koehler.

Pauwelyn , J. 2004. The Puzzle of WTO Safeguards and Regional Trade Agreements. Journal of International Economic Law 7(1): 109-42.

Peters et al. 2011. Growth in Emission Transfers via International Trade from 1990 to 2008. Proceedings of the National Academy of Sciences 108(21): 8903-08.

Peters, G.P., and E.G. Hertwich. 2008. Trading Kyoto. Nature Reports Climate Change 2: 40-41 [doi:10.1038/climate.2008.25].

Stavins, R.N. 2008. A Meaningful U.S. Cap-and-Trade System to Address Climate Change. Harvard Environmental Law Review 32(2): 293-371.

Swallow, S.K., and R.A. Sedjo. 2000. Eco-labeling Consequences in General Equilibrium: A Graphical Assessment. Land Economics 76(1): 28-36.

Teisl, M.F., and R.L. Hicks. 2002. Can Eco-Labels Tune a Market? Evidence from Dolphin-Safe Labeling. Journal of Environmental Economics and Management 43(3): 339-59.

Thøgersen, J., and F. Ölander. 2003. Spillover of Environment-friendly Consumer Behaviour. Journal of Environmental Psychology 23(3), 225-36.

Tietje, C. 1995. Voluntary Eco-labelling Programmes and Questions of State Responsibility in the WTO/GATT Legal System. Journal of World Trade 29(5): 123-58.

United States - Gasoline. Appellate Body Report, United States-Standards for Reformulated and Conventional Gasoline, 29 - 30, WT/DS2/AB/R (April 22, 1996). 
United States-Hot-Rolled Steel. Appellate Body Report, United States-Sunset Review of AntiDumping Duties on Corrosion-Resistant Carbon Steel Flat Products from Japan, WT/DS244/AB/R (December 15, 2003).

United States_-Shrimp/Turtle II. Appellate Body Report, United States-Import Prohibition of Certain Shrimp and Shrimp Products, Recourse to Article 21.5 of the DSU by Malaysia, WT/DS58/AB/RW (October 22, 2001).

United States_-Shrimp/Turtle I. Appellate Body Report, United States-Import Prohibition of Certain Shrimp and Shrimp Products, WT/DS58/AB/R (October 12, 1998).

United States_-Tuna/Dolphin II. Panel Report, United States-Measures Concerning the Importation, Marketing and Sale of Tuna and Tuna Products, WT/DS381/R (September 15, 2011).

United States_-Tuna/Dolphin I. Panel Report, United States-Restrictions on Imports of Tuna (September 3, 1991), GATT B.I.S.D. (39th Supp.).

Understanding on Rules and Procedures Governing the Settlement of Disputes, April 15, 1994, Marrakesh Agreement Establishing the World Trade Organization, Annex 2, 1869 U.N.T.S. 401.

U.S. EPA (Environmental Protection Agency), Office of Inspector General. 2008. Improvements Needed to Validate Reported ENERGY STAR Benefits. Report No. 09-P-0061. Washington, DC. http://www.epa.gov/oig/reports/2009/20081217-09-P-0061.pdf.

Vanclay, J.K., J. Shortiss, S. Auselbrook, A.M. Gillespie, B.C. Howell, R. Johanni, M.J. Maher, K.M. Mitchell, M.D. Stewart, and J. Yates. 2011. Customer Response to Carbon Labelling of Groceries. Journal of Consumer Policy 34: 153-160.

Vandenbergh, M.P., and M.A. Cohen. 2010. Climate Change Governance: Boundaries and Leakage. NYU Environmental Law Journal 18: 221-92.

Vandenbergh, M.P., T. Dietz, and P.C. Stern. 2011. Time to Try Carbon Labelling. Nature Reports Climate Change 1: 4-6.

Vandenbergh, M.P., and A. Steinemann. 2007. The Carbon-neutral Individual. NYU Law Review 82(6): 1673-1745.

Viscusi, W.K. and W.A. Magat. 1987. Learning about Risk: Consumer and Worker Responses to Hazard Information. Cambridge: Harvard University Press. 
Vranes, E. 2010. Climate Labelling and the WTO: The 2010 EU Ecolabelling Programme as a Test Case under WTO Law. In European Yearbook of International Economic Law 2011, Vol. 2, edited by C. Hermann and J.P. Terhecte. Amsterdam, The Netherlands: Springer, 205237.

Watson, D., and S. Moll. 2008. Environmental Benefits and Disadvantages of Economic Specialisation within Global Markets, and Implications for SCP Monitoring. In Proceedings: Refereed Sessions I-II, Sustainable Consumption and Production: Framework for Action, edited by T.G. Ken, A. Tukker, C. Vezzoli, and F. Ceschin. Delft: The Netherlands: TNO Built Environment and Geosciences.

White, P. 2009. Building a Sustainability Strategy into the Business. Corporate Governance 9(4), 386-94.

Wiedmann, T., R. Wood, M. Lenzen, J. Minx, D. Guan, and J. Barrett. 2008. Development of an Embedded Carbon Emissions Calculator: Producing a Time Series of Input-Output Tables and Embedded Carbon Dioxide Emissions for the UK by Using a MRIO Data Optimisation System. London: Department for Environment, Food and Rural Affairs.

York, R., E. Rosa, E., and T. Dietz. 2002. Bridging Environmental Science with Environmental Policy: Plasticity of Population, Affluence and Technology. Social Science Quarterly 83(2): 18-34. 